\title{
Ensinar história com a religiosidade Afrodescendentes e a lei $n$. 10.639/03
}

\author{
Rozalves de LiRA* \\ Maria do Carmo de Melo*
}

\begin{abstract}
RESUMO: Este artigo reflete sobre as perspectivas e desafios para implementação da Lei n. 10.639/03 no sistema educacional brasileiro. Ao alterar a LDB da Educação Nacional (Lei n. 9.394/96), instituiu-se a obrigatoriedade do ensino de História e Cultura Africana e Afro-Brasileira nos currículos escolares das redes pública e privada, o que inclui estudar e reconhecer como legítimas as formas do "sagrado" afrodescendente, garantindo sua ocorrência nas escolas, livre de estigmas e preconceito.
\end{abstract}

Palavras-chave: Religiosidade afrodescendente. Intolerância religiosa. Ensino de história. Lei n. 10.639/03.

\section{Teaching history with religiosity Afrodescendants and Law n. 10,639 / 03}

\begin{abstract}
This article reflects on the perspectives and challenges for the implementation of Law n. 10,639 / 03 in the Brazilian educational system. When changing the LDB of National Education (Law No. 9.394 / 96), the teaching of African and Afro-Brazilian History and Culture was instituted in both public and private school curricula, which includes studying and recognizing as legitimate the forms of Afrodescendant "sacredness", by guaranteeing it is taught in schools, free of stigma and prejudice.
\end{abstract}

\footnotetext{
* Mestre em Educação pela Universidade de Pernambuco. É graduado em História (licenciatura plena). Atuou como coordenador pedagógico e gestor adjunto nas redes pública e privada de ensino profissionalizante, fundamental e médio de Pernambuco. Nazaré da Mata, PE- Brasil. E-mail: <rafalira04@hotmail.com>.

* Doutora em Educação pela Universidade do Minho é Professora adjunta da Universidade de Pernambuco, no âmbito da Graduação e da Pós-Graduação (Scricto-Sensu e Lato-Sensu). É também coordenadora de Graduação da UPE - Campus Mata Norte. Nazaré da Mata, PE- Brasil. E-mail: <mcbmelo@upe.com.br>.
} 
Keywords: Religiosity of afrodescendants. Religious intolerance. Teaching of history. Law nº 10.639/03.

\section{Enseñar historia con religiosidad}

Los afrodescendientes y la ley $n .^{o}$ 10.639/03

RESUMEN: Este artículo reflexiona sobre las perspectivas y los desafíos para implementar la Ley n. ${ }^{-}$10.639/03 en el sistema educativo brasileño. Al modificar la LDB de la Educación Nacional (Ley n.․ำ 9.394/96), se instituyó la obligatoriedad de la enseñanza de Historia y Cultura Africana y Afrobrasileña en los currículos escolares de las redes pública y privada, lo que incluye estudiar y reconocer como legítimas las formas de lo "sagrado" de los afrodescendientes, asegurando su existencia en las escuelas sin estigmas ni prejuicios.

Palabras clave: Religiosidad afrodescendiente. Intolerancia religiosa. Enseñanza de Historia. Ley n. ${ }^{\circ}$ 10.639/03.

\section{Enseigner 1'histoire avec la religiosité Afrodescendants et loi n. 10.639/03}

RÉSUMÉ: Cet article porte sur les perspectives et les défis de la mise en oeuvre de la Loi n. 10.639/03 dans le système scolaire brésilien. Avec le changement de la Loi des Lignes Directrices et de Bases de l' Éducation Nationale (Loin. 9.394/96), a été mise en place l'obligation d'enseigner l'Histoire et la Culture Africaine et Afro-Brésilienne dans les programmes scolaires des réseaux publics et privés, ce qui inclut d'étudier et de reconnaître comme légitimes les formes de "sacré" afrodescendant, assurant leur occurence dans les écoles, exempts de stigmates et de préjugés.

Mots-clés: Religiosité Afrodescendante. Intolérance Religieuse. Enseignement de l'Histoire. Loi n. 10.639/03. 


\section{Introdução}

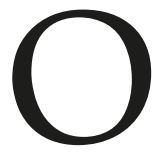

Brasil figura no âmbito internacional e nacional, como um país cuja marca maior seria a plurietnicidade e multiculturalidade, pois se trata de uma nação de dimensões continentais e de formação histórica e social marcada pelo cruzamento de culturas e povos que coabitam de forma "ordeira e pacífica". No entanto, as relações entre os diferentes agrupamentos étnico-culturais participantes da formação brasileira têm sido marcadas pela assimetria nas relações de poder e no acesso à cidadania. Cotidianamente no Brasil, negros, indígenas e outras categorias sociais excluídas são vitimados pelo preconceito e discriminação nos mais diversos espaços sociais, entre eles a escola, que muitas vezes silencia ou parece desconhecer esta realidade.

Uma das formas através da qual se manifesta o preconceito na escola [que se imagina democrática, mas que, muitas vezes, discrimina e exclui, contribuindo, entre outros aspectos, "para reproduzir a ordem social hegemônica, não tanto pelos pontos de vista que fomenta, mas por distribuir de forma regulada o capital cultural" (BRINHOSA, 2009, p. 39)], dá-se, entre outras formas, no tratamento dispensado à aplicabilidade da Lei n. 10.639/03. O desafio de superar limitações provenientes da falta de conhecimento da história e das culturas africanas e afro-brasileiras, especialmente, na escola, é fulcral na formação, hoje, considerando o fosso entre as políticas educacionais de Estado e a sua implementação, especialmente no que tange à adequação da formação inicial dos professores e à obrigatoriedade do ensino de História e Cultura Africana e Afro-Brasileira nos currículos escolares das redes pública e privada de ensino.

Este artigo reflete sobre as perspectivas e desafios para a implementação da Lei $n$. 10.639/03 no sistema educacional brasileiro. O estudo delimita as tensões geradas a partir do silêncio dos currículos oficiais, no que se refere à manifestação da diversidade de identidades religiosas e o exclusivismo religioso na escola.

Tomando como amostragem o discurso de professores(as) de História na educação básica de duas escolas do município pernambucano de Goiana (uma da rede estadual e outra da privada) e sua relação com o conteúdo da Lei n. 10.639/03, o estudo de abordagem qualitativa, teve como método a aplicação de questionário, e revelou que ainda há muitos desafios para a implantação deste recurso político-jurídico nas escolas. Até mesmo para que haja, através deste recurso, a discussão sobre o tema, bem como a implantação de conteúdos e práticas de ensino que abordem as religiosidades afrodescendentes. As respostas obtidas sinalizaram a necessidade de se rever os currículos de licenciatura e a formação continuada, bem como as práticas dos docentes, quando se almeja a construção de uma educação multicultural e que fortaleça a cidadania e o combate ao racismo eà intolerância religiosa no âmbito educacional e, consequentemente, no espaço social. O desafio da função de formar deve levar o docente a pesquisar os conhecimentos próprios do ensino, sendo necessária a atualização desse conhecimento a partir de novas leituras, discussões, pesquisas e produções que consigam revelar o contexto complexo nos quais os professores(as) estão inseridos. 


\section{As complexas relações de ideias no contexto da escola}

Interessa notar que, vez ou outra, o silêncio que a escola brasileira pratica acerca das mais diversas formas de preconceito no cotidiano, e em especial no relacionado às religiões afrodescendentes, descamba em violência verbal, pedagógica e/ou psicológica, seja através de discursos inflamados e combativos contra estas religiosidades e seus adeptos, piadas, xingamentos e "brincadeiras sutis", por meio do bullying, da exclusão das atividades e brincadeiras ou da mutilação de livros didáticos que abordam o tema, por parte dos professores ou dos alunos, isto quando não geram violência física (ARAÚJO, 2015; NASCIMENTO, 2012).

Para exemplificar a veracidade nas limitações da escola em lidar com elas e como, infelizmente, são corriqueiras nas nossas instituições de ensino, trazemos um caso ocorrido numa unidade da Rede Estadual de Educação da cidade de Goiana, Pernambuco, em outubro de 2015, quando uma criança de 11 anos, filho de um babalorixá ${ }^{1}$ da cidade, depois de desentender-se com colegas de classe, foi física e verbalmente agredido por três deles aos gritos de "vamos quebrar este catimbozeiro safado e filho do Diabo". Neste caso, fica claro que, entre as motivações para a violência escolar, estava a afiliação religiosa do aluno.

Porém, o mais preocupante no expediente acima narrado fora o tratamento que a escola dispensou ao caso. Preocupados com a repercussão pública e a visibilidade negativa que isso traria para a instituição, os gestores e o professor que testemunhara o fato sugeriram ao pai da criança que tivesse paciência e mantivesse o caso em sigilo para evitar "exposição desnecessária" e que no dia 20 de novembro, data em que se festeja a Consciência Negra no Brasil, a escola abriria as portas para que o seu Candomblé fizesse uma apresentação de música e dança.

O caso é no mínimo emblemático e revela a falta de habilidade em lidar com este e outros tipos de situação que envolvem intolerância, racismo e preconceito, visto que a ocorrência, em momento algum fora tratada como intolerância religiosa, mas como "mais um" caso de agressão física na escola. Ao invés de a equipe docente e gestora da unidade problematizarem a situação e aproveitarem o ocorrido para discutir entre professores e alunos os motivos que levam determinados credos e seus adeptos a serem respeitados e outros hostilizados, a escola optou por aguardar quase um mês após o episódio até o dia 20 de novembro e abrir suas portas para que ilús ${ }^{2}$ e atabaques soassem, crendo que com isto estava construindo a cidadania e contribuindo para a formação de sujeitos tolerantes com a diversidade.

Imagina-se perante o narrado a angústia e constrangimento vivenciados pela criança vitimada pela ofensa, possivelmente, não possuindo mecanismos para enfrentar o episódio negativo experimentado em sua unidade escolar com relação às suas crenças. Além disso, este evento revela que as religiosidades afrodescendentes são vistas muitas 
vezes na escola como manifestações "culturais e artísticas" folclorizadas e alegóricas, jamais como um culto legítimo, isto na melhor das hipóteses, pois em boa parte dos casos penetram as esferas educacionais de forma deturpada e marcada pelo preconceito e intolerância.

Esta rotina de práticas excludentes e discriminatórias denuncia que as relações inter-étnicas e culturais na educação brasileira ainda são marcadas pela assimetria no acesso à legitimidade e ao poder por parte de alguns grupos, necessitando portanto de ações regulares que reflitam sobre estas questões e promovam práticas de combate a elas. Episódios como esse revelam a perversidade de um imaginário social que, quase sempre, é reproduzido por um modelo de educação que insiste em negligenciar ou silenciar práticas pedagógicas relacionadas à presença e importância das religiões de matriz africana e afro-brasileira no espaço da escola. Estudar as tensões reveladas nessa situação, certamente, contribuirá para conhecer e discutir meios que ajudem a desconstruir a cultura que não consegue lidar com o pluralismo religioso.

As religiosidades existentes e alteridades deveriam ser um dos objetos formativos dos docentes, assim, poderiam paulatinamente superar as dificuldades, na abordagem do diálogo inter-religioso, que traz na esteira de discussões temas referentes ao racismo de matriz étnico-racial e ao preconceito social, em específico no relacionado aos negros escravizados e seus descendentes.

\section{A promoção da cidadania na diversidade}

Compreender o mundo, compreender a sociedade, compreender a si mesmo e compreender as relações socioculturais deve ser competência necessária no processo de ensino-aprendizagem. Embora não seja fácil, nem para os professores nem para os alunos, é possível aprender a ser mais, quando se aprende a conhecer, a fazer e a viver com outros, especialmente, no direito à diferença no contexto do multiculturalismo. A escola é o espaço em que se deve envolver os alunos na construção de saberes que garantam a igualdade, do ponto de vista do exercício da cidadania e da diversidade como direito, pois,

[...]é um lugar de formação cultural e científica dos alunos em articulação com a diversidade social e cultural, por um processo ensino-aprendizagem centrado na formação de processos psíquicos visando o desenvolvimento cognitivo, afetivo e moral dos estudantes, e é nessa condição que se transforma em instância de democratização e promoção da inclusão social (LIBÂNEO, 2015, p. 645).

Já foram feitas várias tentativas de sistematizar uma lógica para compreender a complexidade da escola, porém Libâneo destaca-se ao pensar a escola enquanto experiência que permite a participação das diferenças em seu espaço, pois articula a "diversidade 
social e cultural". Por tal razão, a diferença e o convívio com ela, enquanto participante, pressupõe a ocorrência do conflito de ideias, opiniões, maneiras de se comportar, enxergar e entender o mundo, dialogando com os ideais democráticos e incluindo socialmente a todos.

Sendo o conflito causado pela diferença inerente ao processo educativo, este quadro demanda da escola habilidades e saberes que devem ser acionados para mediá-lo. A postura amparada em padrões e princípios éticos e solidários constitui uma das principais responsabilidades da instituição na formação de uma cultura tolerante, de apreço e de respeito pela diversidade e pela própria inclusão social. Em época de recrudescimento da intolerância mundo afora, representa um dos grandes desafios da educação contemporânea.

As práticas pedagógicas e a formação de docentes no Brasil encontram-se alicerçadas sob os ditames de uma tendência na educação internacional que é a da inclusão do debate sobre a diversidade na escola baseada na perspectiva teórica multiculturalista emergente após os anos de 1990 (SILVA, 2015). Partindo do princípio de que a diversidade é algo benéfico para o corpus da sociedade, em educação, esta corrente de pensamento toma como norte o questionamento acerca do caráter "monocultural e homogeneizador" de sua dinâmica, "tanto no que se refere aos conteúdos do currículo quanto às relações entre os diferentes atores, às estratégias utilizadas nas salas de aula, aos valores privilegiados" (MOREIRA; CANDAU, 2013, p. 21), buscando desenvolver estratégias de enfrentamento a este quadro.

Como sinais deste contexto, em 1996, a LDB da Educação nacional (Lei n. 9.394) apontou a necessidade de o ensino ser orientado para a promoção da cidadania, incluindo-se o respeito à diversidade, quando, em seu artigo 22, afirma ser caminho a ser perseguido na educação básica: "[...] desenvolver o educando, assegurar-lhe a formação comum e indispensável para o exercício da cidadania" visando romper com a educação de caráter eurocêntrico até então vivenciada no Brasil. Em 1997, os Parâmetros Curriculares Nacionais, sugerem a necessidade de inclusão, sob a égide da transversalidade, da pluralidade cultural no ensino e na formação de professores, reconhecendo que "provocar essa demanda específica na formação docente é exercício de cidadania. É investimento importante e precisa ser um compromisso político-pedagógico" (BRASIL, 2013, p. 123).

Especificamente na área do ensino de História, no bojo destas modificações, há um redimensionamento das percepções epistemológicas, filosóficas e metodológicas que a orientam, numa perspectiva de valores, defendida por Rusen, que deve funcionar como "fonte de arbitragem nos conflitos e como objetivos que orientem a ação" (SCHMIDT; BARCA; MARTINS, 2011, p. 55). Tal redimensionamento precisa levar os educandos a relacionar os valores de determinada situação, interpretá-los e ao seu conteúdo moral e avaliar a situação nos termos dos valores aplicáveis (Ibidem). Nesse sentido, as práticas de sala de aula desse componente curricular passam a ser orientadas com mais 
comprometimento às questões do presente. Prevalece, assim, a ideia de que o passado deve ser interrogado a partir de questões que inquietam o cotidiano. Caso contrário, o estudo da História seria confundido com acúmulo de informações sem sentido sobre o passado, o que significa

tomar como referência no estudo questões sociais e culturais, assim como problemáticas humanas que fazem parte de nossa vida, temas como desigualdades sociais, raciais, sexuais, diferenças culturais, problemas materiais e inquietações relacionadas a como interpretar o mundo (KARNAL, 2010, p. 24).

A ideia de Karnal aproxima-se da proposta de Paulo Freire que visava promover a educação com base na cultura. Aliada a esta concepção surge a consciência cada vez maior de que o ensino de História através do "estudo das raízes da sociedade ajudará as crianças a apreciar as crenças, as culturas e os usos sociais de outras sociedades que estudem" (SCHMIDT; CAINELLI, 2009, p. 29), contribuindo para fortalecer o reconhecimento da diversidade.

Entretanto, as lutas para o estabelecimento de uma educação plural e inclusiva que possa de fato valorizar e reconhecer o sentido da diversidade, em específico sobre a experiência e importância dos africanos e da afrodescendência na formação nacional, perpassa todo o século $X X$, tendo como destaque a atuação de alguns movimentos da sociedade civil organizada, com especial protagonismo do Movimento Negro Unificado (BRASIL, 2013).

Este processo tem como emblema a promulgação da Lei Federal de n. 10.639, assinada pelo então presidente Luís Inácio da Silva, em janeiro de 2003, alterando a LDB da Educação de n. 9.394/96, o que acrescentou a este estamento jurídico a obrigatoriedade do ensino de História e Cultura Afro-Brasileira e Africana ${ }^{3}$ no currículo da educação básica nacional, reservando à disciplina escolar História importante papel no novo cenário.

Em 2004, o Conselho Nacional de Educação aprova a resolução CNE/CP, 1/2004, que institui as "Diretrizes Curriculares para a Educação das Relações Étnico-Raciais e para o Ensino de História e Cultura Afro-brasileira e Africana" e, entre outras recomendações, garante à disciplina de História protagonismo na perseguição de seus objetivos, entre os quais consta: “o reconhecimento e a valorização da identidade, história e cultura dos afro-brasileiros, bem como a garantia de reconhecimento e igualdade de valorização das raízes africanas da nação brasileira" (BRASIL, 2013, p. 78).

A partir de então, a valorização das chamadas "africanidades brasileiras", 4 que inclui as religiosidades afrodescendentes, passa a participar oficialmente da agenda educacional de nosso país e a disciplina de História assume protagonismo neste processo. Em diferentes graus, desde então, cursos de formação de professores e escolas de todo o País passam a revisitar conceitos, práticas pedagógicas e rotinas educacionais, buscando orientar ações para o fortalecimento das relações sociais igualitárias, as quais requerem 
o reconhecimento da contribuição de mulheres e homens africanos e seus descendentes para a formação histórico-social brasileira (BRASIL, 2013).

Passada mais de uma década desde a emergência deste instrumento político-jurídico e reconhecidas as dificuldades, impasses, sucessos e fracassos no exercício da Lei 10.639/03 no âmbito escolar, algo que chama a atenção é uma relativa resistência, em se trabalhar a temática da cultura afrodescendente, mais especificamente a das religiões e religiosidades afro-brasileiras e de matrizes africanas no cotidiano das práticas de ensino, possivelmente, pelo fato de que para trabalhar o significado dessa Lei e suas exigências é preciso conhecer e refletir sobre sua dimensão histórica.

A resistência em se tratar destes temas no âmbito das escolas assume os mais diversos contornos, em geral permeados pelo preconceito causado pelo desconhecimento, pela formação eurocêntrica dos professores, pela afiliação político-religiosa de alguns atores do processo, e até mesmo pelo racismo. Interessa notar que tais expedientes não são observados, em específico nas aulas e conteúdos de História, quando, por exemplo, o professor ou a escola precisam tratar das práticas religiosas pertencentes a outros grupos étnicos sóciohistóricos, como gregos e romanos, por exemplo.

Sendo assim, o elenco de tais atitudes está na contramão do esforço educativo nacional, com protagonismo especial da disciplina escolar História, que visa o fortalecimento dos valores democráticos, da cidadania, o apreço pela diversidade e o combate à desigualdade racial na educação, constituindo espaço de embates pelo exercício de poder e legitimidade na esfera educacional, onde participam práticas, conceitos e procedimentos.

\section{Cultura e religiosidade afrodescendente em Pernambuco}

Independente do grupo étnico de pertencimento, autorreconhecimento ou identificação, a experiência sóciohistórica brasileira pressupõe a ocorrência de elementos oriundos da cultura africana e afrodescendente, que em maior ou menor grau participam do cotidiano e do modo de vida de todos os brasileiros, fortalecendo as referências culturais dos grupos sociais em sua heterogeneidade e complexidade e os ideais de fortalecimento de uma sociedade democrática e multicultural, onde ocorrem as mais distintas manifestações do comportamento humano.

Entre as formas de manifestação das africanidades brasileiras em Pernambuco, podemos destacar, entre outras, a ocorrência de espaços de exercício da religiosidade afrodescendente, expressos em núcleos, casas ou terreiros de Umbanda, Candomblé e Jurema, caracterizados por práticas que os identificam tanto com os formatos de religiosidade afro-brasileira quanto com a religiosidade de matriz africana.

Em Pernambuco, de acordo com Roberto Motta (1999), estas religiões podem ser divididas em quatro grupos: Jurema/Catimbó, Umbanda, Candomblé/Xangô e 
Xangô-umbandizado. Em nosso Estado o termo Xangô (nome do orixá que representa os ideais de justiça e retidão e o poder do fogo e do trovão), em virtude da popularidade deste orixá, "tomou sentido mais amplo e passou a significar o próprio terreiro" e por consequência a religião (VALENTE, 1977, p. 81).

Embora o termo Xangô seja utilizado em Pernambuco de forma genérica para aludir a todos os núcleos de religiosidade afrodescendente sem distinção, importa frisar que estas formas de crer não se apresentam de maneira uniforme, havendo diversas concepções e formas de praticá-las, que podem variar de acordo com a vertente na qual está agrupada a casa ou terreiro. No caso da Umbanda, por exemplo, ainda segundo Motta (1999), não existe uma religião classificada como Umbanda, mas várias umbandas, cada uma delas com uma diversidade imensa de crenças e ritos.

A adoção deste aporte teórico auxilia na desconstrução da ideia de que as religiões afrodescendentes são uma unidade e que Umbanda, Jurema e Candomblé "são uma coisa só", embora para aplicação do questionário com os(as) professores(as), optamos por trabalhar o conceito guarda-chuva da religiosidade afrodescendente. ${ }^{5}$

Diversos pensadores acusam as religiosidades afrodescendentes de serem "religiões genuinamente nacionais", pois reúnem as formas de crer e agir perante o sagrado dos elementos majoritariamente participantes da formação social e histórica do Brasil: índios, europeus e africanos, sendo, por tal razão, também descritas como religiões mestiças e sincréticas (ROCHA JUNIOR, 2011).

Refletindo sobre estes aspectos, Vagner Silva afirma que ao absorver elementos provenientes de outros credos e praticar o sincretismo, as religiosidades afrodescendentes acabaram tentando solucionar as problemáticas decorrentes da formação social heterogênea do Brasil, "com vistas a produzir uma síntese que refletisse, no nível religioso, as contribuições (e contradições) dos grupos formadores de nossa experiência social e histórica" (SILVA, 2005, p. 125).

O conjunto de práticas culturais e religiosas acima elencadas demonstra de forma emblemática elementos que tipificam a inventividade criativa do brasileiro em se tratando do universo sagrado, pois organiza, através do aparato do discurso teológico, o que aparentemente não poderia ser organizado, a saber, a diversidade de matrizes étnico-raciais, sociais e culturais que compõem o Brasil.

Pensadores e cientistas sociais são unânimes em reconhecer a riqueza de tais práticas enquanto elementos que expressam de forma bastante simbólica o que chamamos de brasilidade, dignas de serem festejadas e motivo de orgulho enquanto riqueza patrimonial do povo brasileiro. Entretanto, as práticas em diversos setores da sociedade brasileira no relacionado às manifestações da religiosidade afrodescendente têm se mostrado opostas a esta concepção. Importa informar que estas práticas são históricas, mudando apenas os agentes promotores da perseguição e desmoralização dos cultos. A guisa de exemplo, trazemos uma citação de Nina Rodrigues, pioneiro nos estudos sobre os cultos 
afro-brasileiros, que em fins do século XIX já denunciava o tratamento que as autoridades e a imprensa dispensavam a estas religiosidades:

$\mathrm{Na}$ África, estes cultos constituem verdadeira religião de estado (...) No Brasil, na Bahia, são ao contrário considerados práticas de feitiçarias, sem proteção nas leis, condenadas pela religião dominante e pelo desprezo, muitas vezes apenas aparentes, é verdade, das classes influentes que, apesar de tudo, as temem. (...) Hoje, cessada a escravidão, passaram elas a prepotência e ao arbítrio da polícia não mais esclarecidas do que os antigos senhores e aos reclamos da opinião pública que, pretendendo-se fazer de espírito culto e forte, revela a toda hora a mais supina ignorância do fenômeno sociológico (RODRIGUES, 1976, p. 139).

Este tipo de tratamento também é verificado no campo da educação, seja através das práticas de pesquisa e escrita, seja nas práticas docentes e curriculares. Infelizmente, prevalece no senso comum (e pasmem!) e entre muitos educadores a ideia de que estas religiões não gozam do mesmo grau de legitimidade de outras formas de crer - por exemplo, o catolicismo e mais recentemente o protestantismo, cujas histórias e análises têm sido fartamente registradas e, em muitos casos, divulgadas nas escolas como parte das práticas curriculares de alguns componentes curriculares oficiais ou até como matéria na modalidade de ensino religioso confessional (SILVA, 2005).

O princípio adotado neste texto é de que não existem religiões superiores ou inferiores, corretas ou incorretas, boas ou más, pois estas concepções baseiam-se mais em pontos de vista individuais e julgamentos de valor subjetivo, do que em princípios teóricos e éticos. Frequentemente, as religiões são julgadas com base em (pre)conceitos e visões de mundo oriundas de outras religiões, que geralmente as enxergam como opositoras.

Estas concepções não podem permear o cotidiano das práticas de ensino, pois significam reforçar velhos chavões e preconceitos educacionais e a manutenção do currículo de caráter monocultural, que tem aversão à diversidade. Neste sentido, o ensino de História deve ser conduzido de forma a "demonstrar e confirmar que nossa cultura nacional não possui uma única fonte, mas muitas; que nossa linguagem e nossos costumes não se desenvolveram isolados" (SCHMIDT; CAINELLI, 2009, p. 29). Ensinar História é ter consciência do poder desta área do saber enquanto formadora da cidadania e para a democracia, possível de combater as mais distintas formas de preconceitos e injustiças. Ou seja, a consciência histórica é um pré-requisito necessário a esse ensino.

\section{Sobre ensinar História com a religiosidade afrodescendente}

Com o objetivo de conhecer o pensamento dos(as) professores(as), para intensificar o debate, o este trabalho intencionou contribuir para o avanço da discussão e da 
reflexão, promovendo encontros sistemáticos de estudos. Pretendeu, ainda, analisar os saberes permeados nas práticas de sala de aula e as concepções multiculturalistas presentes na escola. O propósito fora aprofundar a discussão da Lei 10.639/03, centrada na religiosidade afrodescendente.

Preocupados em perceber o alcance e a percepção da Lei por parte de professores(as) goianenses, e em especial sobre as possibilidades de utilização de elementos da religiosidade afrodescendente em consonância com a referida legislação, foram entrevistados seis profissionais do componente curricular de História que atuam na educação básica em duas instituições de ensino da cidade, uma pública estadual e uma privada.

Adotamos como método para a coleta de dados a aplicação de questionário aberto com questões de caráter objetivo (sim ou não e marque um " $x$ ") e também questões cujas respostas envolviam comentários livres. Os questionários foram entregues aos(às) professores(as), com um prazo de três dias para sua devolução. Ao todo foram apresentadas oito questões sobre a implementação da Lei na escola, o grau de conhecimento/ relacionamento com ela e com a religiosidade afrodescendente, e percepções sobre resistência e preconceito ao tratar estes elementos.

Inqueridos(as) sobre se percebiam formas de resistência em se trabalhar temas referentes à cultura e história africana e afro-brasileira entre professores de História da educação básica, três professores, dentre os seis entrevistados, responderam positivamente e outros três negaram haver qualquer tipo de resistência. Os resultados verificados na apuração da pesquisa, especificamente sobre este ponto, permitem perceber, entre outros aspectos, que, o que ocorre com professores goianenses de História na educação básica é que nem sempre há consenso entre eles, em relação ao trabalho e à aplicabilidade da Lei 10.639/03, algo que não destoa muito do cenário nacional (ARAÚJO, 2015), visto que o respeito aos termos da Lei, em alguns casos, torna-se extremamente difícil de praticar, possivelmente, em virtude de uma formação inicial de professores hegemonicamente monológica e de coabitação, contrariando a realidade de pluralidade cultural e, ainda, a compreensão do necessário viés democrático que exige, em uma sociedade plural, o respeito aos diferentes grupos e culturas que a constituem, evitando a permanência

de um pensamento que produz o apagamento dos afrodescendentes da história e da cultura brasileira. Apagamento que sempre foi realizado em nome da construção de uma nação. Uma nação sob a ideologia de mestiça, mas europeizante, necessariamente embranquecedora. A própria mestiçagem, na forma como é pensada, não como fato, mas como ideologia, contém a fórmula da eliminação das afrodescendências (CUNHA JUNIOR, 2008, p. 85).

Assim sendo, é fácil perceber o peso dessas ideologias no pensamento social e educacional brasileiro, chegando a funcionar como fortes entraves na promoção de uma educação multicultural orientada pela resolução das questões étnico-raciais referentes ao racismo, ao preconceito e à intolerância religiosa. Pois, mesmo com os avanços 
implementados legalmente, "as escolas brasileiras ainda têm como base o modelo eurocêntrico e monocultural de educação" e continuam a praticar uma educação "discriminatória, preconceituosa e excludente, que tenta unificar e homogeneizar saberes, e, na maior parte das vezes, negando saberes milenares" (ARAÚJO, 2015, p. 221), oriundos de grupos socialmente desfavorecidos, como é o caso das manifestações religiosas da afrodescendência.

Entretanto, nossa posição neste trabalho parte do pressuposto de que, enquanto ideologias, a mestiçagem e o ideal de embranquecimento da população, assim como o racismo e a intolerância, são ensinados e aprendidos e não algo nato, logo, podem ser superados através de práticas educativas de História, conscientes de sua responsabilidade enquanto promotoras dos ideais de multiculturalidade, cidadania e combate ao racismo, das quais, cremos, a Lei 10.639 constitui importante ferramenta de problematização, desconstrução e enfrentamento.

Questionados sobre se havia algum tipo de resistência em se trabalhar temas referentes à religiosidade afrodescendente entre professores de História da educação básica, diferente da resposta à questão anterior onde as opiniões se dividiram, todos os seis participantes foram unânimes em responder que sim. Convém salientar que a elaboração da maioria das perguntas aplicadas utilizou, a exemplo desta, sempre a terceira pessoa do singular (entre professores de História da educação básica), dando certa impessoalidade aos resultados, embora conduzissem os docentes a refletir sobre sua própria prática enquanto acionavam as percepções sobre as práticas dos colegas de profissão. Neste sentido parece ter sido vivenciado pelos(as) participantes um trânsito entre "reflexões do eu", " práticas do outro" e "práticas de si mesmo".

No relacionado à última questão, a unanimidade nas respostas revela o lugar ocupado pelas religiões de matriz africana e afro-brasileira no imaginário coletivo dos(as) professores pesquisados(as) e nas suas práticas escolares, sinalizando entre outros motivos, o fato de possuírem estereótipos em relação a essas religiões, em geral marcadas pela assimetria no acesso ao currículo e a visões deturpadas sobre as mesmas, com julgamentos de valor baseados em dogmas religiosos, já que, por serem consideradas "religiões de transe, de sacrifício animal e de culto aos espíritos (portanto, distanciados do modelo de religiosidade dominante em nossa sociedade), têm sido associados a certos estereótipos" (SILVA, 2005, p. 13) e participado do cotidiano escolar, em boa parte dos casos, sob a marca da negação, do preconceito e da ilegitimidade.

Esta realidade também encontra como emblemas teóricos que a fundamentam o ideal de embranquecimento da população, que neste caso manifesta-se nos aspectos culturais e religiosos, pois há forte associação histórica entre brancura da pele e cristianismo, numa relação que permite entrever que,

De acordo com D’Adesky, a educação no Brasil é marcada pela hegemonia cultural euro-brasileira e pela exclusão das heranças culturais afro-indígenas dos currículos 
escolares, que subtraem das classes populares importantes instrumentos de etnicidade, autonomização social e cidadania impondo-lhes a branquidade (CAPUTO, 2012, p. 242).

Considerando o pensamento de Caputo, fica claro a necessidade de a escola assumir-se, desempenhando sua verdadeira função, desatrelada da visão hegemônica, sendo espaço não só de tolerância e de cruzamento da diversidade, mas como lugar de discussão, reflexão e criação de conhecimento útil.

Como questão complementar à anterior, foi perguntado sobre os possíveis motivos para a resistência em tratar do tema religiosidade afrodescendente entre professores de História da educação básica, cujas respostas apresentaram opiniões bastante diversas. Convém esclarecer que no caso desta pergunta, foram apresentados no próprio formulário de questões alguns dos "possíveis motivos" para a ocorrência deste quadro, listados a seguir:

1. Racismo, em virtude da origem étnica (negra) desta forma de religiosidade.

2. Preconceito, em virtude da origem social (arregimenta parcela significativa de seus fiéis entre as camadas mais baixas da população) e por isso trata-se de religião dita popular.

3. Preconceito, em virtude das origens extra cristãs deste formato de crença, causado pelo poder hegemônico do cristianismo no Brasil.

4. Preconceito, causado pelo conhecimento de algumas práticas deste formato de religiosidade (sacrifício de animais, uso da magia e adivinhação).

5. Desconhecimento quanto ao objeto.

6. A maioria dos profissionais da educação básica não sabe de que forma a religiosidade afrodescendente pode contribuir de maneira significativa para o processo de ensino-aprendizagem.

7. O lugar deste formato de crença nas escolas já é garantido através da vivência de datas comemorativas, como: Dia da Abolição da Escravidão no Brasil (13 de maio), Dia do Folclore (24 de agosto) e Dia Nacional da Consciência Negra (20 de novembro).

Solicitados(as) que apontassem, pelo menos duas, entre as razões elencadas, todos(as) os(as) participantes optaram por apontar três dos "possíveis motivos", que segundo seu entendimento limitariam o trabalho com elementos da religiosidade afrodescendente nas práticas de ensino de História, alcançando-se desta forma os seguintes resultados: os "motivos" de número um, dois e quatro, tiveram três marcações cada, 
respectivamente; o de número seis obteve duas marcações; e os de número cinco e sete, foram apontados apenas uma vez cada. Quanto ao "motivo" de número três, houve unanimidade entre os seis profissionais inqueridos quanto à sua marcação, evidenciando que na visão de professores(as) de História do município de Goiana, o preconceito, em virtude das origens extra cristãs deste formato de crença, seria a principal razão de não se trabalhar tais elementos nas práticas de ensino, embora também reconheçam que fazem parte do estudo de temas referentes à história e à cultura dos africanos e seus descendentes no Brasil.

As escolhas dos educadores(as) trazem implícitas práticas pedagógicas que ainda se revelam distanciadas de uma formação que tenha como princípio o respeito à realidade multicultural. Revela o desafio de superar a sub-representação da presença, na escola, das culturas, especialmente, das religiões de origem africana, bem explícito na ideia de que o preconceito existe em virtude das origens extra cristãs. Nesse sentido, as tentativas de pluralismo religioso podem redundar em um universalismo religioso.

Refletindo sobre estes aspectos, Santos (2012) lembra que a questão religiosa vem funcionando fortemente para barrar a aplicação da Lei 10.639 nas escolas, visto que segmentos de religiões evangélicas e da Igreja Católica, ao correlacionarem História e Cultura Africana e Afro-Brasileira aos aspectos religiosos de matriz afrodescendente, diferentes dos valores de sua cosmovisão, os combatem no processo educativo através de professores(as), funcionários(as), gestores(as), alunos(as) e/ou familiares dos(as) alunos(as).

Tais atitudes promovem uma demonstração clara de intolerância e desrespeito ao Estado nacional de caráter laico, antiprosélito e multicultural. Tais atos se dão também na escola, pois as instituições religiosas "influenciam o comportamento dos sujeitos que as compõem e, por conseguinte, outros espaços de convívio por eles frequentados" (ARAÚJO, 2015, p. 225). Neste sentido, ocorre uma "satanização" e "demonização" dos conteúdos que tratam da história e da cultura afrodescendente nos meios extraescolares, o que implica silenciar ou praticar discursos e práticas pedagógicas preconceituosas e intolerantes.

Os resultados alcançados com a aplicação desta pesquisa, embora careçam de uma análise mais aprofundada, apresentam-nos a constatação de que ainda há muito a ser feito no âmbito das práticas dos(as) professores(as) para que os objetivos da Lei $n$. 10.639/03 sejam alcançados e para que de fato tenhamos uma educação que prime pelos princípios éticos de tolerância, cidadania e democracia, através dos quais as diferenças, percebidas numa perspectiva multicultural, sejam participantes do cotidiano escolar e das práticas dos(as) professores(as) na perspectiva de construção de uma educação histórica significativa e que fortaleça os ideais de cidadania, democracia e direitos humanos no combate ao racismo, discriminação e intolerância religiosa. 
Ao apontar motivos como o preconceito de matriz social, étnica e religiosa, a intolerância com um culto não cristão e não hegemônico e o racismo como principais motivos para a resistência em tratar da religiosidade afrodescendente no ensino de História, professores(as) goianenses sinalizam a ocorrência de uma realidade que, infelizmente, pontua o universo educacional de todo o País, apontando também a necessidade de revisita à formação inicial e continuada dos professores, tendo em vista o atendimento aos recursos jurídicos disponíveis e necessários para fazer frente ao racismo e ao preconceito na educação, que tolhe o crescimento intelectual e emocional de milhares de educandos(as).

Ao permitir que estas práticas se repitam em seu cotidiano, a escola perpetra uma violência simbólica grave não apenas com relação a estas crenças e a seus adeptos, mas contra a cultura, as leis e a democracia.

A violência simbólica, aqui referida, constitui-se no conjunto de regras não faladas sobre o que pode ser validamente enunciado ou percebido dentro do processo educacional. Essas regras operam em todos os níveis e modalidades de ensino, uma vez que elas são legitimadas e costumam passar despercebidas como violência, [...] (BRINHOSA, 2009, p. 39).

Assim, a violência simbólica praticada pelo processo descrito "atua em todo o campo da educação e da cultura, na qual aqueles a quem falta o gosto 'correto' são discretamente excluídos, relegados à vergonha e ao silêncio" (Ibidem). A instituição de um padrão religioso "correto" e digno de penetrar as propostas curriculares e pedagógicas causa impactos negativos não apenas nos indivíduos que estão diretamente associados ao sagrado afrodescendente na condição de adeptos e sacerdotes e que, vale salientar, também estão na escola na condição de professores(as), gestores(as), funcionários(as), alunos(as) e pais de alunos(as), mas principalmente impacta na construção de uma educação orientada à valorização da diversidade, cidadania e democracia, pautada no reconhecimento do direito constitucional do outro de manifestar suas formas de crer da maneira que desejar, como também na viabilização de sua penetração nas instituições escolares como elementos participantes da formação histórica e social do Brasil e sem a marca da vergonha, da exclusão e do silêncio.

Refletindo sobre a relação entre religiões afrodescendentes e educação em texto intitulado de forma bastante sugestiva $O$ candomblé está na escola. Mas como?, Stela Caputo afirma:

Crianças e jovens de candomblé estão na escola, mas a grande maioria oculta uma guia do Oris̀à [sic] que ama [...].[...]. Alguns chegam a inventar uma doença para justificar a cabeça raspada para o santo, ou fazem a Primeira Comunhão, para não serem perseguidas. Isso não é sincretismo, é silenciamento (2013, p. 179). 
Compete largamente para tais formas de silêncio e ocultamento assumidos por muitos alunos(as) e outros atores escolares adeptos das religiosidades afrodescendentes acerca de suas crenças, as práticas pedagógicas e curriculares monoculturais e monorreligiosas perpetradas pelas escolas e que apresentam-nas de forma limitada, excludente e marcada pelo filtro da intolerância.

O quadro analisado permite perceber que ainda há muito a ser feito para que a cidadania plena e as mais diferentes manifestações do crer, do pensar e do comportamento humano, a exemplo das religiosidades afrodescendentes, participem da escola, livres de estigmas e preconceitos e para que o recurso político-jurídico de n. 10.639 possa de fato ser aplicado nas práticas educacionais. Entretanto, convém destacar que entre as questões que fizeram parte do inquérito, uma solicitava aos(às) professores(as) que através de um comentário destacassem maneiras através das quais os elementos da religiosidade afrodescendente pudessem contribuir de forma significativa para o processo de ensino-aprendizagem de sua área disciplinar, surpreendendo-nos o comentário do professor Roberto ${ }^{6}$ (Rede Estadual de Educação de Pernambuco e Rede Municipal de Goiana), para quem:

\begin{abstract}
A História é agraciada de forma amplamente rica e multicultural por movimentos e manifestações populares originários das religiões afrodescendentes, tendo em mente a contribuição sociocultural, histórica e antropológica de tais religiões, sendo praticamente impossível falar de África e afro-brasileiros sem citar suas crenças e seus orixás. Podem-se desenvolver trabalhos e projetos sobre os valores desta religião, em especial no relacionado ao culto aos elementos da natureza (orixás), trabalhando de forma transversal e interdisciplinar, temas como preservação dos recursos hídricos, poluição, desmatamento, etc.
\end{abstract}

Consideramos importante transcrever este comentário do professor como elemento textual auxiliar no fechamento temporário das discussões acerca deste tema, por perceber em sua fala instrumentos sinalizadores de possibilidades e esperança de dias melhores para o tratamento das religiosidades afrodescendentes nas aulas de História, mas para tanto se faz necessário que a escola reconheça o seu verdadeiro papel social e que os personagens da escola mobilizem-se em prol da cidadania na escola e na sociedade.

\title{
Considerações finais
}

“Magia negra”, " primitivismo", "coisa de gente ignorante”, "demoníacas”, " diabólicas", "macumba", "satanismo" são algumas das expressões e adjetivos mais comumente utilizados para aludir às religiosidades afrodescendentes na escola. Ao fazer uso de tais referências, em geral, os atores da educação apelam para sua própria visão de mundo.

Isto é o que mostram os elementos apontados pelos professores(as) goianenses entrevistados como entraves em se trabalhar estes fenômenos na educação e, desta forma, 
limitar a aplicação da Lei n. 10.639/03, perpetuando o racismo e o preconceito, pois ao afirmarem que é o perfil religioso de alguns(as) professores(as), gestores(as) e alunos(as), que enquanto evangélicos(as) e/ou católicos(as), não sabem ou não querem lidar com estes fenômenos na escola, demonstram que muitos acabam se esquecendo do caráter laico e antiprosélito da educação nacional, e ignoram o fato de que a educação no Brasil é definida por lei como plural e inclusiva.

Interessa lembrar que as interrelações entre concepção de currículo, prática docente e poder na educação são amostras em microescala do social (SOUZA, 2013), concebendo-se, portanto, esta interligação; e convém pensar que, se as religiosidades afrodescendentes encontram no âmbito social oposição e sofrem perseguição, preconceito e intolerância, é ingênuo não crer que estas atitudes também se manifestarão nas práticas educacionais, fazendo-se necessária a ocorrência de políticas específicas e práticas pedagógicas que façam frente a este desafio. Um desafio que implica a negativa da diversidade, inerente ao universo escolar e aos ditames condizentes ao componente curricular de História, entendida como instrumento de fortalecimento e formação cidadã, democrática e multicultural.

Recebido em 03/01/2017 e aprovado em 14/07/2017

\section{Notas}

1 Literalmente "pai no orixá", em iorubá, idioma ritual das religiões afrodescendentes no Brasil, popularmente utilizado na acepção de "pai de santo", o sacerdote principal das casas de culto (RIBEIRO, 2014, p. 44).

2 Tambores, em iorubá, instrumento de percussão utilizado nas religiões afrodescendentes.

3 Alterada em 2008 originando a Lei nº 11.645/08 que acrescentou a obrigatoriedade do Ensino de História e Cultura Indígena (BRASIL, 2013).

4 "Ao dizer africanidades brasileiras, estamos nos referindo às raízes da cultura brasileira que tem origem africana. Dizendo de outra forma, estamos, de um lado, nos referindo aos modos de ser, de viver, de organizar suas próprias lutas, próprias dos negros brasileiros, e de outro, às marcas da cultura africana que, independentemente da origem étnica de cada brasileiro, fazem parte do seu dia a dia" (SILVA, 2008, p. 151).

5 Conceito que engloba todas as formas de crença com presença de elementos culturais e religiosos identificados com a experiência sóciohistórica africana no Brasil. Esta classificação engloba dois subconceitos: religiões afro-brasileiras - aquelas que se desenvolveram no Brasil a partir da experiência africana em contato com elementos religiosos de indígenas e europeus (o caso da Umbanda, Jurema, algumas manifestações do Catolicismo popular e algumas variantes do espiritismo Kardecista); e religiões de matrizes africanas aquelas que reivindicam o estatuto de africanidade e que teriam se formado por meio da junção de cultos de distintos povos africanos, de diferentes etnias e regiões da África, e que, no Brasil se teriam fundido com pouca influência de grupos étnicos não africanos (o caso dos chamados Candomblés-nação, que rei- 
vindicam pertencimento às "nações africanas" Nagô, Ketu, Jeje, Mina, Xambá, Congo, Moçambique e/ou Angola) (XAVIER, 2009).

Os nomes foram trocados.

\section{Referências}

ARAÚJO, J. A. A efetivação da Lei 10.639/03 na percepção dos militantes/professores negros baianos. Revista Eletrônica de Educação, v. 9, n. 3, p. 216-232, 2015. Disponível em: http://www.reveduc.ufscar. br/index. Acesso em 3 mai. 2016.

BRASIL. Ministério da Educação, Secretaria de Educação Continuada, Alfabetização, Diversidade e Inclusão - SECADI. Plano nacional de implementação das diretrizes curriculares nacionais para educação das relações étnico-raciais e para o ensino de história e cultura afro-brasileira e africana. Brasília: MEC, SECADI, 2013.

BRINHOSA, M. C. A função social e pública da educação na sociedade contemporânea. In: LOMBARDI, J. C. (org.). Globalização, pós-modernidade e educação: história, filosofia e temas transversais. 3. ed. Campinas, SP: Autores Associados; Caçador, SC: UnC, 2009.

CAPUTO, S. G. Ogan, adósu òjè, ègbónmi e ekedi - O candomblé está na escola. Mas como?. In: MOREIRA, A. F.; CANDAU, V. M. (orgs.). Multiculturalismo: diferenças culturais e práticas pedagógicas. 10. ed. Petrópolis, RJ: Vozes, 2013.

. Educação nos terreiros: e como a escola se relaciona com crianças de candomblé. Rio de Janeiro: Pallas, 2012.

CUNHA JUNIOR, H. História e cultura africana e os elementos para uma organização curricular. In: BARROS, J. F. P., OLIVEIRA, L. F., CANEN, A. (orgs.). Todas as cores na educação: contribuições para uma reeducação das relações étnico-raciais no ensino básico. Rio de Janeiro: Quartet, FAPERJ, 2008.

KARNAL, L. (org.). História na sala de aula: conceitos, práticas e propostas. 6. ed. São Paulo: Contexto, 2010.

LIBÂNEO, J. C. Formação de professores e didática para desenvolvimento humano. Educação e realidade, Porto Alegre, v. 40, n. 2, p. 629-650, abr./jun. 2015. Disponível em: http://www.seer.ufrgs.br/ index.php/educacaoerealidade/issue. Acesso em 9 mai. 2016.

MOREIRA, A. F.; CANDAU, V. M. (orgs.). Multiculturalismo: diferenças culturais e práticas pedagógicas. 10. ed. Petrópolis, RJ: Vozes, 2013.

MOTTA, R. M. C. Religiões afro-recifenses: ensaios de classificação. In: CAROSO, C.; BACELAR, J. (orgs.). Faces da tradição afro-brasileira. Rio de Janeiro: Pallas, 1999.

NASCIMENTO, S. L. Relações raciais e Ensino Religioso no Brasil. Belo Horizonte: Nandyala, 2012.

RIBEIRO, R. Cultos afro-brasileiros do Recife - um estudo de ajustamento social. In: HUTZLER, C. R. (org.). René Ribeiro e a antropologia dos cultos afro-brasileiros. Recife: Ed. Universitária da UFPE, 2014.

ROCHA JUNIOR, E. A. História e cultura afro-brasileira. Recife: 3D, 2011.

RODRIGUES, R. N. Os africanos no Brasil. São Paulo: Cia. Editora Nacional, 1976. 
SANTOS, D. L. J. “Tá repreendido em nome de Jesus!": religião, identidade e conflito com a implementação da Lei 10.639/2013. Curitiba: Appris, 2012.

SCHMIDT, M. A.; CAINELLI, M. Ensinar história. São Paulo: Scipione, 2009. 2011.

.; BARCA, I.; MARTINS, E. R. (orgs.). Jorn Rusen e o ensino de História. Curitiba: Ed. UFPR,

SILVA, P. B. G. Aprendizagem e ensino das Africanidades brasileiras. In: MUNANGA, K. (org.).

Superando o racismo na escola. Brasília: Ministério da Educação/SECAD, 2008.

SILVA, T. T. Diferença e identidade: o currículo multiculturalista. In: Documentos de identidade: uma introdução às teorias do currículo. 3. ed. Belo Horizonte: Autêntica Editora, 2015.

SILVA, V. G. Candomblé e Umbanda: caminhos da devoção brasileira. 5. ed. São Paulo: Selo Negro, 2005.

SOUZA, M. E. V. (org.). Relações raciais no cotidiano escolar: diálogos com a Lei n. 10.639/2003. 2. ed. Rio de Janeiro: Rovelle, 2013.

VALENTE, W. Sincretismo religioso afro-brasileiro. 3. ed. São Paulo: Cia Editora Nacional, 1977.

XAVIER, J. T. P. Limites conceituais no estudo das religiões afrodescendentes. In: SANTOS, G.; SILVA, M. P. (orgs.). Racismo no Brasil: percepções da discriminação e do preconceito no século XXI. São Paulo: Ed. Fundação Perseu Abramo, 2009. 